\title{
Teaching Writing in Indonesian Language Classes with a Genre-Based Approach (GBA): Between Hope and Reality (An Analysis of Lesson Plans in the Curriculum 2013 Classroom)
}

\section{Botifar}

Tadris Indonesian Study Program, Department of Tarbiyah, State College for Islamic Studies Curup, Jalan Dr. A.K. Gani No 01, Bengkulu 39119, Indonesia

\section{Abstract}

This article discusses a number of concepts related to the teaching of writing in the classroom by using the curriculum of 2013. The aim was to map the teaching of writing in Indonesian language subjects based on language teaching theory comparing to

Corresponding Author:

M. Botifar

maria.botifar@yahoo.co.id

Received: 6 April 2018

Accepted: 3 May 2018

Published: 26 July 2018

Publishing services provided by

Knowledge E

(c) M. Botifar. This article is

distributed under the terms of

the Creative Commons

Attribution License, which

permits unrestricted use and

redistribution provided that the

original author and source are credited.

Selection and Peer-review under the responsibility of the ISLLE 2017 Conference Committee.

\section{G OPEN ACCESS}

\section{Introduction}

Language teaching methods have changed over the centuries, beginning with classical methods, including the method known as the "grammar-translation method." Classical methods focused on grammatical rules, memorizing vocabulary, various declinations and conjunctions, the translation of the text, and doing written exercises. One of the characteristics of the classical methods is that teaching language is taught by using the mother tongue and just a little bit of the target language, because there is a preference for using difficult texts.

Furthermore, the classical methods begin to exhibit many weaknesses, so researchers begin to focus on aspects of teaching speech as in direct methods. Until audiolingual method in the 1940s remains at the focus of the emphasis on speech practice. Only in the 2oth century did language teaching become more directed toward 
the function of language itself, namely communication, also known as communicative language teaching (CLT).

The communicative language teaching approach has become more famous for bringing the perspectives of social constructivism to the central language focus for interactive communication between individuals, each of which has a social and cultural identity. To that end, Hymes distinguishes between linguistic competence and communicative competence, which are two different things; if linguistic competence with regard to forms of language and communicative competence related to the knowledge that allows one to communicate functionally and interactively [1].

Canale and Swain describe four components that make up the concept of communicative competence, namely: 1) grammatical competence, which includes: knowledge of lexical items and rules of morphology, syntax-semantics grammar-sentence and phonology; 2) discourse competence, the complement of grammatical competence, the ability to link sentences in the range of discourse and to form a meaningful whole series of utterances that can be shaped to a simple conversation to the long written text; 3) sociolinguistic competence, which is knowledge of the rules of language and discourse of social culture, which requires an understanding of the social context in which language is used; 4) strategic competencies that describe verbal and nonverbal communication strategies that can be used to congestion the offset in communication due to insufficient competence [2].

Communicative competence was updated again in the gos with the concept of Bachman that is also known as "language competence." Bachman divides language competence into two general categories: organizational competencies, which include grammatical competence and textual competence, and pragmatic competence, which includes questionnaire competence and sociolinguistic competence [3]. The latter language competence makes language teaching fulfill to a greater extent the needs of learners' speech.

The era of language teaching that upholds language competencies provides direction to the curriculum in Indonesia. Currently, Curriculum 2013, which became the basis of language teaching in the classroom, is being developed further according to students' language needs. Students learn to use communicative events rooted in the text. Text becomes a tool for learning the language because the text contains a lot of information, not only the elements in the text itself but also the elements outside the text, such as culture.

Teaching that uses text is known as "genre-based learning." Genre-based learning combines the use of several approaches. It is related to communicative, which guides 
students toward achieving the purpose of using language effectively and systematically by linking the language and context. Genre-based learning is also linked to the grammar-translation method, in which the teacher gives expressions in the language to show how the language operates.

One of the most effective language teaching elements that use genre-based learning is the teaching of writing. Teaching writing for a class that uses genre-based Learning in Curriculum 2013 is easier to understand for students in direct contact with the sample text to be written. Although writing skills are more difficult in a second language than in the first language, according to Zamel's study, learners must write in advance with the new first language later translated into a second language. How far the teaching of writing is applied in Curriculum 2013 with a genre-based learning approach will be described later in this article.

\section{Methods}

Teaching writing as part of language teaching can be a benchmark for the success of language teaching because teaching writing demands the productivity that comes from teaching the other language skills. To that end, teaching writing has a high degree of difficulty because it requires learners not only how to out the issue or ideas, but also how to put the ideas into a text that can be read and understood. Teaching writing should at least meet the principles of language teaching, which are mapped into three parts, namely cognitive, socioaffective, and linguistics. In the cognitive part, teaching writing should consider four principles, namely: 1) the principle of automation regarding how to produce a language derived from the environment unconsciously; 2) the principle of meaningful learning, which associates learning with whatlearners know; 3) the principle of anticipated appreciation, where students' learning is generally controlled by reward; 4) the principle of intrinsic motivation to do something for the sake of the thing itself; and 5) the principle of investment strategies, where every student has different methods and strategies to acquire language.

As regards the socioaffective part, teaching writing has characteristics that are associated with the emotional control each individual or as students to socialize with each other. There are four principles related to the socioaffective part, namely: 1) the language ego principle means that if someone learns to use a second language, he also develops a second identity (ways of thinking, feeling, and acting) associated with the second language that he has used; 2 ) the principle of self-confidence means learner confidence in his ability will be a success factor in achieving the goals; 3 ) the principle 
of risk taking means students are not afraid to use the target language; 4) the principle of the relationship between language and culture in human life, meaning language and culture are inseparable because the language is part of the culture, so it becomes very important in second language learning. Indeed, language is also an important factor in the development and preservation of culture.

In terms of linguistics, there are principles that relate to the language itself and how the students face the complex language system. Those principles are as follows: 1) The principle of mother tongue influence means that this principle emphasizes the importance of the mother tongue of students in an effort to learn a second language as the mother tongue of students has a strong influence on the acquisition of the target language system. This influence can be supportive or interrupt the production process and new understanding of the language, and it turns out that the disruptive effects tend to be more prominent. 2) The inter-language principle highlights the influence of the forms of one language on another language. Second language learners tend to be influenced by the effect of earlier forms of language when they are trying to master a second language. Sometimes the original language is transferred negatively, then there is interference. However, it is also important to remember that the original language of second language learners is often also transferred positively, making it easier to learn a second language. 3) The principle of communicative competence means emphasizing that communicative competence is the goal of language classes. Given that communicative competence is the goal of language classes, learning needs to be pointed towards all its components: organization, pragmatic, strategic, and psychomotor skills. Communicative goals will be achieved either through the use of a language that is not merely for the purpose of accuracy but also for eloquence or smoothness and usefulness in the real world.

From the principles of language teaching above it can be understood that the implementation of the teaching of writing in the classroom should reflect learning that promotes cognitive development, socioaffective, and linguistics. The principles of language teaching are very suited to a learning strategy that integrates with the text, as well as a genre-based approach, which has many similarities to contextual teachinglearning.

To that end, the teaching of writing in the classroom by using a genre-based approach cannot be separated from the social activities of students in learning under the guidance of teachers. Teaching writing becomes an unconscious effort on the part of students to improve their writing competence. The teacher provides the facility of a text that can stimulate students to find a lot of things from the text. Teachers 
should emphasize the importance of developing students' awareness that every text is a unique creation by a unique writer that is relative to a certain group of people and context.

Richard and Renandya describe the stages that must be considered by teachers in teaching writing to develop the writing competence of students successfully [4], including:

1. Stage 1: Ensuring the goals and constraints of institutions/agencies

The obstacles often faced by teachers in teaching writing include a) curriculum, b) textbooks used, and c) how to evaluate the students' ability.

2. Stage 2: Deciding the principle theory

Teachers should be able to see multiple views of different theories about language, language learning, and the nature of learning. Teachers should determine the clarity of the theory used in language learning to be able to articulate clearly so it can be put into the syllabus.

3. Stage 3: Planning the content

Planning the content or materials is an important part of teaching writing. Teachers should choose such content, personal experience, social issues, cultural issues, literature or anything else in the teaching of writing. However, planning the content is not related to practice writing by specifying paragraph types according to the model and essay form prescribed. This is not correct because it uses a unique type of writing as a tool for language learning. Teachers have to restore the initial concept of writing as a valuable tool for learning not only about learning materials but also about language. Writing is not a demonstration lesson for discovery learning. Writing is not just developing ideas but also examines the ideas and the language used. If the teacher asks students to analyze, manipulate, and imitate the text, it does not provide space for students to practice finding a suitable form and content in their own way.

4. Stage 4: Weighing the element

Teachers should consider which parts of the writing are priorities to be developed. Writing consists of many parts, including organization, originality, style, smoothness, accuracy, and proper use of rhetorical forms of discourse. Certainly, teachers cannot teach all these things: They should prioritize and consider the elements that correspond to the needs of students and the basic theory used. 
5. Stage 5: Arranging the syllabus

After deciding on the content and weighing the elements, the next step is how to regulate the content and learning experiences in the classroom. The syllabus becomes part of determining the success of teaching writing. There are many options in making a syllabus depending on the combination approach that is used, what proportions to use, the purpose of use, theoretical principles, and institutional constraints.

There is a kind of lesson plan for writing a learning syllabus, including:

(a) Structural: Early-level writing can be taught around grammar and sentence patterns. Teaching is focused on the structural pattern or genre in writing a paragraph with a topic sentence, description, analysis, etc.

(b) Functional: Learning to write may be presented around rhetorical activities: storytelling, explaining, writing an autobiography, comparing and contrasting, categorizing, defining, arguing, persuading, or supporting the thesis with examples, illustrations, and other evidence.

(c) Topical: Learning to write around a theme, such as health, education or courage abstraction or success.

(d) Situational: Learning to write may be organized around situational transactions, such as applying for a job, writing an open letter in the newspaper, writing business memos, or writing an essay to pass in learning.

(e) Skills and Processes: Learning to write by using skills and processes associated with generating ideas, organizing ideas, revising, writing fluently, writing an effective start and ending with, or developing arguments to convince, the reader.

(f) Task: Learning to write can be arranged around problem-solving activities, such as producing a class magazine, comparing the structure of a written text for a different audience and purpose, writing, editing, and producing a game, etc.

\section{Stage 6: The election of materials}

Richard and Renandya describe the steps in the selection of materials [4], namely:

(a) Topics: Are the topics involved interesting to the students? Are the topics based on student experience? Is the matter in the good books of images, activities, and questions the student out of topic? Are the topics according to the students' culture? Is the content relevant and interesting? 
(b) Types of writing: Are students to write an essay, a letter, or a paragraph?

(c) Opportunities and instruction in methods of developing ideas: Which of the following are included: brainstorming, free writing, arranging, mapping, elaborating? Which are appropriate for the students?

(d) Instructions on the principles of rhetorical organization: What information is given to help students organize various kinds of writing, i.e. letters, descriptions, narrations, expositions, and argumentation, and which do the students need to practice?

(e) Opportunities for collaboration: Is part of the working group? f. Opportunities for revision: Are students encouraged and directed to draft? Does the book give instructions on what to do at various stages? Does the curriculum allow for a revision of the essay?

(f) Instruction in editing and proofreading: What can students learn from a book about how to edit their writing? Is any instruction given in finding and editing grammatical errors?

7. Stage 7: Prepare activities and roles

Learning to write prioritize activities and the role of students. To that end, teachers only need to prepare the teaching writing, which is based on what students can do, not what the teacher did. The teacher prepares classrooms that are centered around the students.

8. Stage 8: Selecting the type and method of feedback

Choosing the type and method of this feedback are related to responding to the results of students' writing. For a large class, not every article should be corrected by the teacher. Students can write a journal, log response to read or write freely with the aim of generating ideas and improving the accuracy. Meanwhile, teachers must also have a variety of methods to provide comments or converse with the author. And most importantly, teachers must select the type of response time and the number of students in the classroom.

9. Step 9: Evaluate the learning

Teachers can use a sentence and essay tests to evaluate student progress. In addition, an increasingly popular form of evaluation to incorporate student evaluations is the portfolio. Portfolios are assessed by other teachers so that students are willing to revise to present their best work. 
10. Stage 10: Reflecting the experience

Teachers must remain at the forefront in conducting writing. The results of the process of reflection on class activities become good material for a teacher to use in teaching writing activities. Teachers should have sufficient experience so they will find a new, effective and noted its impact on teaching writing.

The stages of teaching writing above clearly provide the steps to write the theoretical and practical, which can help students improve their writing competence. Teachers can follow the practical steps but still based on the theory that serves as a guide in teaching writing. The smart teacher will choose teaching writing strategies that can meet the needs of students in teaching writing.

The writing process does not separate the writing activities with products that are written, only lead students to proceed in writing activities. Writing activities not only emphasize the products but the main thing is the writing process. For that, through the various stages of the process undertaken to build oriented writing instruction in the effective performance and will affect the performance. Having a teaching program that is oriented toward effective performance means that teachers need to teach systematically.

Teachers must consider students' ability to solve problems associated with the writing process. That process will enable students to achieve certain goals at every stage of the drafting process. Thus, the process of writing in the classroom can be interpreted as a teaching program that provides a learning experience that is designed to help students understand the nature of writing in every corner. The process of writing as a class writing activity combines four basic stages: planning, drafting, revising, and editing. This is followed by the external phase, namely responding, evaluating, and post-writing. The four basic stages of writing are described below:

1. The planning stage

The planning stage is the stage of pre-writing, which includes the following activities: a) group brainstorming, i.e. activities out ideas about the topic; b) grouping, which involves words activities related to the stimulus provided by the teacher; c) freewriting quickly, an activity in which the words and phrases related to the topic are written down freely and quickly; d) using the WH questions, namely activities to develop questions with who, why, what, where, when and how about the topic.

2. Drafting 
At this stage, the students focus on smooth writing and are not focused on grammatical accuracy or neatness. One dimension of good writing is the ability of the writer to the reader visualize.

\section{Responding Stage}

Responding to students' writing has been central in improving the implementation of the writing process. Responding to an activity intervenes between the drafting and revision.

\section{Revising Stage}

The revising stage involves reviewing the text on the basis of the feedback given. Students examine what has been written to see how effective it has been in communicating meaning to the reader.

\section{Editing Stage}

At this stage, students engage in text smoothing in preparing the final draft to be evaluated by the teacher. Students edit on their own, or in collaboration with colleagues, to improve the grammar, spelling, punctuation, diction, sentence structure, and accuracy of textual material to support such as quotations, examples, and the like.

\section{Evaluating Stage}

Evaluating the students' writing can be done analytically or holistically. Criteria for writing that students know in advance so that the end of the writing process and the writing refers to the criteria.

From the process of writing referred to above, students are encouraged to understand the nature and the truth of writing itself. The process of writing that reflects the learning activities of the teacher that understood both theoretically and practically, because writing skills involve the ability of these two things. The writing process is observed by considering the goal of writing as a product. While this type of writing only as a medium is not the purpose of writing. Content writing is more valuable than direct students in terms of the shape and type of writing.

\section{Results}

Teaching writing in the classroom by using a genre-based approach is implemented in Curriculum 2013 for learning English among Indonesian subjects. A genre is a form 
of speech or writing that is conventionally associated with "communicative events". Participants in these communicative events tend to set goals with stringent norms that govern what can be said and what cannot be said to be in the background of a given genre. With the approach of this genre, teaching writing is based on a text. Information from the text becomes the content to be studied. A text can provide a lot of information, which is the form of the text itself, starting from its characteristics, the grammar, and the rules in the form of the text itself, so students can learn a lot from a text.

For Curriculum 2013 in the subject of the Indonesian language, the text types that are studied by class VII are observation text, description text, exposition text, explanatory text, and story text, while the text types studied by class VIII are moral story/fable text, review text, discussion text, procedure text, and biographical text. Indeed, there are many types of text that distinguish the genre. A genre is constituted by external criteria, nonlinguistic, and traditional. However, the text type is based on internal criteria, linguistics, and the characteristics of the text itself. A genre is defined as a category that is based on external criteria such as certain readers, objectives, and specific activities. A genre is a conventional and cultural grouping based on the properties of the text, not on lexical or grammatical features such as text type. Differences in the nature of the genre and the text from the beginning have spawned a different perception in Curriculum 2013. From the concepts above, it is clear that Curriculum 2013 is closer to the text-based approach. The difference between genre and text is also shown in the table 1:

From the genres and texts above, the kinds of text that are taught in Curriculum 2013 do not reflect the types of genre that become the basis for the division of the text itself. The division of the text based on the genre needs to be reinforced again in Curriculum 2013, because the types of text represent genres that become characteristic of writing.

The learning experience in activity-based learning to write with this text reflects learning by improving aspects of grammar, structure, and characteristics of the text and drawing up a text. The learning activities of the first semester in class VIII are as follows:

Theme: Hold the purpose through creativity

Basic Competence: 
TABLE 1: Examples of genres and text types.

Genre
Food recipes
Personal letter
Advertisement
Police reports
Student essays
Formal letter
Formal letter
Beads News
Health Brochure
Students' tasks
Biology Textbooks
Film Review

\begin{tabular}{|c|}
\hline Text Types \\
\hline Procedures \\
\hline Anecdote \\
\hline Description \\
\hline Description \\
\hline Exposition \\
\hline Exposition \\
\hline Problem-solution \\
\hline Recount \\
\hline Procedure \\
Recount \\
\hline Report \\
\hline Review
\end{tabular}

3.1 Understanding moral tale/fable text, reviews, discussions, procedures, and biographies either through oral or written.

4.2 Arrange moral tale/fable text, reviews, discussions, procedures, and biographies in accordance with the characteristics of the text that will be made either orally or in writing.

\section{Indicators:}

3.1.1 Identify the structure or procedure text form to sharpen the understanding.

3.1.2 Identify language elements/features of the procedure text to sharpen the forms.

4.2.1 Mention how to prepare a procedure text in accordance with the structure of the text.

4.2.2 Establish procedures in accordance with the structure of the procedure text with the correct spelling.

\section{Learning Activities:}

First Meeting ( $2 \times 40$ minutes)

Main Activity (60 minutes)

\section{Observing}


1. Students read the text Pembibiton Mawar dengan Teknik Stek.

2. Students listen to the explanation of instruction activities about the subject in outline.

\section{Asking}

1. Students ask questions with regard to the observations made.

2. Answering questions from the text Pembibitan Mawar dengan Teknik Stek.

\section{Collecting Data (Experiment/Exploring)}

1. Looking for information from various sources about the text of the procedure.

2. Looking for information to identify the structure and language features of the procedure text.

3. Looking for information to identify how to arrange procedure text.

4. Students process the information that has been collected in the group.

\section{Associating}

1. Students discuss identifying the structure or form of the procedure text Pembibiton Mawar dengan Teknik Stek.

2. Students discuss identifying language features in the procedure text Pembibiton Mawar dengan Teknik Stek.

3. Students discuss how to arrange a complete procedure text in an orderly and logical fashion.

4. Students exchange information about the structure of procedure text and language features with active response by students from other groups.

\section{Second Meeting ( 2 × 40 minutes)}

\section{Main Activity (60 minutes)}

\section{Communicating}

1. Students listen to the explanation of instruction activities about the subject in outline. 
2. Students present the results of discussion group classically about: the structure of the text and language features of procedure text in a complete, orderly, and logical fashion.

3. Giving an opinion on the presentation that is made and responded to by the presented group.

4. Summing up the important points that appear in learning activities that have been done such as: written observations report on the structure and language features of procedure text in a complete, orderly, and logical fashion.

5. Ask about things that have not been understood, or the teacher throws some questions to the students.

\section{Third Meeting}

\section{Main Activity (60 minutes)}

\section{Creating}

1. Students write/compose procedure with regard to structure and language features of procedure text with good and correct spelling.

2. Students mutually edit the procedure texts that have been made by their friends.

3. Students write back the procedure text that has been edited by their friend.

From the writing activities, it can be seen that students do writing activities by just doing structural aspects of a writing activity. The structure only revolves around grammar, spelling, form, systematic and preparation. Students learn to write with the aim of preparing a procedure-type text. Students do writing activities with the ultimate goal of not the product of a process of writing itself, while writing activities are not just an activity to understand the learning material but to understand about the language itself. One interpretation of the writing activities in Curriculum 2013 is that they make language learning rigid, monotonous, and tortuous because the students are forced to learn the ropes of existing structures. Language loss of communication function in learning. The interaction of students with the language is limited by the structure of the text into their content, while learning to write does not demonstrate learning but the invention learning.

Therefore, an understanding of the writing concept in Curriculum 2013 become out of the target so that the theory of writing does not serve as the basis for teachers in implementing learning to write in the classroom. In fact, the understanding of the 
concept of writing must begin with the theory of writing appropriate to the truth of writing itself, such as language learning is not learning the kind of writing. The kind of writing is not a destination but only the media for writing content according to the needs of students. Therefore, writing not only develops ideas but also examines the ideas and the language used. If the teacher asks students to analyze, manipulate, and imitate a text, it does not provide space for students to practice with a view to finding a suitable form and content in their own way. So the concept of writing, according to Tarigan, is a process of describing a language so that the message conveyed by the author can be understood by readers are not achieved [5].

The writing activities referred to above also illustrate that the students' learning experience has focused on the structure and language of the text. Students learn to identify language features of a procedure text. In fact, in the structure of the Indonesian language, there are no essential distinguishing language features between one text and another. If the language features of each text are mapped, it will be the same because the Indonesian language does not recognize differences in grammar elections due to different factors of the text types. Every text will be met by language features that are related to the pattern of S-P-O sentences, spelling, punctuation, capitalization, diction, and other elements that relate to grammar. Thus, the language features will not characterize the text because it is global.

On the other hand, as a result of the centralization of teaching writing on language features and textual elements only, the communicative competence of the students is not fully involved. In writing the above activities, it is not seen any activity involving the four language skills are underutilized in learning to write. Students read to find language features and elements of the text, not the meaning of the passage. Students talk about finding language features and elements of the text, not about the meaning of the text. While the communicative competence by Hymes was not "creativity is determined by the rules", if it is done then it is not enough to explain the rules of social and functional languages [1]. The rules of social and functional language are an important aspect for students in making the language more flexible.

Judging from the stages of the writing process, the learning activities above do not reflect the stages of this process, which is based on the truth of writing itself as the activities of the process and the product. The stages of writing begin with the planning stage that starts from the invention of the subject. The most difficult part is to find a topic to write about. While in Curriculum 2013 students presented literary topic have been determined and analyzed the topic of the language features and text form. Indepth discussion on the topic is not done by teachers, as teachers simply engage using 
a structural approach only. This means that learning strategy language is a behavior or action used by learners so that language learners are more successful, directed and fun not done.

It is not much done when teaching writing by focusing on structural approach. Likewise, the process of revision and editing is part of the writing process. Teachers should provide feedback as a starting material for teachers to conduct revision and editing. However, in Curriculum 2013 this is not found. The process of revision and editing is done at the end of activities without consideration or feedback from the teacher.

\section{Conclusion}

Restoring the truth in teaching writing as a part of learning a language that emphasizes cognitive, socioaffective, and linguistic principles needs to be considered by the teacher. Teachers should look at learning writing not just by demonstrating learning that emphasizes the product, but learning that integrates processes and products. Students presented the experience of writing that laid the foundation of language itself, so that the communication aspect was not neglected. The writing process was at the core of the teaching of writing itself, from planning and drafting to providing feedback, revising, editing, and evaluating. Stages of the writing process to be bypassed in a systematic step by step. Curriculum 2013 with its genre-based-approach remains an approach that should be based on an integrated language learning. This means that it not only focuses on the aspects of language and elements of the text, but also lays the foundation for a communicative learning strategy. Language communicative competence is an approach that allows students to interact actively, not only with text but also with other language users. Text is only a tool for understanding the language, so the text is not the purpose of learning.

\section{Acknowledgement}

Authors would like to thank State College for Islamic Studies Curup for facilitated this research.

\section{Conflict of Interest}

Authors declare that there is no conflict of interest in this research. 


\section{References}

[1] Hymes DH: On Communicative Competence. In J. B. Pride \& J. Holmes (Eds.), Sociolinguistics. London: Penguin. 1972.

[2] Canale M, Swain M: Theoretical Bases of Communicative Approaches to Second Language Teaching and Testing. Appl Linguist. 1980; 1(1): 1-47.

[3] Bachman LF: Fundamental Considerations in Language Testing. Oxford: Oxford University Press. 1990.

[4] Richards JC, Renandya WA: Methodology in Language Teaching: An Anthology of Current Practice. Cambridge: Cambridge University Press. 2002.

[5] Tarigan HG: Menulis sebagai Suatu Keterampilan Berbahasa. Bandung: Penerbit Angkasa. 1986. 